\title{
Drug utilization study of drugs used in the management of post-partum hemorrhage at a tertiary care hospital
}

\author{
G. N. S. Sangeetha Lakshmi ${ }^{1 *}$, U. Bharathi ${ }^{2}$, Vadlakonda Sruthi ${ }^{1}$, Arige Geervani ${ }^{3}$
}

\begin{abstract}
${ }^{1}$ Department of Pharmacology, Osmania Medical College, Koti, Hyderabad, Telangana, India ${ }^{2}$ Department of Pharmacology, Government Medical College, Kadapa, Andhra Pradesh, India ${ }^{3}$ ESIC Medical College, Sanathnagar, Hyderabad, Telangana, India
\end{abstract}

Received: 14 May 2020

Revised: 19 June 2020

Accepted: 02 July 2020

\section{*Correspondence:}

Dr. G. N. S. Sangeetha Lakshmi,

Email: asangeethalakshmi@yahoo.co.in

Copyright: (c) the author(s), publisher and licensee Medip Academy. This is an open-access article distributed under the terms of the Creative Commons Attribution Non-Commercial License, which permits unrestricted non-commercial use, distribution, and reproduction in any medium, provided the original work is properly cited.

\begin{abstract}
Background: Postpartum haemorrhage remains a major cause of both maternal mortality and morbidity worldwide, uterotonic drugs such as oxytocin, with or without ergometrine, have been used to prevent PPH. The objective to study the drugs used in the management of post-partum haemorrhage at a tertiary care hospital.

Methods: An observational and cross-sectional study design was adopted for this study. The case sheets of 100 patients presenting in active stage of labour to the labour room in a tertiary care hospital were analysed.

Results: In the prescriptions analysed from the patients in the labour room, drugs used to prevent PPH are oxytocin and misoprostol. Oxytocin is the most commonly prescribed drug to prevent PPH in the study group. It is a life-saving drug to prevent PPH and thereby maternal mortality. In the study group having 103 patients, a total of 81 patients received only $10 \mathrm{IU}$ oxytocin IM and 14 patients received $10 \mathrm{IU}$ oxytocin IM and $600 \mathrm{~g}$ misoprostol to prevent PPH.

Conclusions: Oxytocin is an essential drug included in the WHO essential drug list and in the national list of essential medicine, so it shouldn't have been dealt in such a biased manner.
\end{abstract}

Keywords: Postpartum haemorrhage, Oxytocin, Maternal mortality, Restricted manufacture

\section{INTRODUCTION}

Postpartum haemorrhage is a major cause of both maternal mortality and morbidity in the world with an estimated mortality rate of 140,000 per year or one maternal death every four minutes. ${ }^{1}$ Postpartum haemorrhage (PPH) accounts for $25 \%$ of all pregnancyrelated deaths. ${ }^{1} \mathrm{PPH}$ occurs in $5 \%$ of all deliveries, majority of maternal deaths occur within four hours of delivery indicating that it is a consequence of third stage of labour. ${ }^{2}$ WHO estimates that of the 5,29,000 maternal death occurring every year, $1,36,000$ or $25.7 \%$ of death takes place in India and two third of these maternal death occur after delivery, PPH being the most commonly reported complication. ${ }^{3}$ The unacceptably high maternal death of 540 per 100,000 live births in India in last few decades remains a major challenge to the government. ${ }^{3}$

WHO defines PPH as blood loss of $500 \mathrm{ml}$ or more in first 24 hours of delivery. ${ }^{1}$ In developing countries like India where most of the women are anaemic their condition is further aggravated by increased demand during pregnancy and blood loss during $3^{\text {rd }}$ stage of labour? The average blood loss after a caesarean delivery (CD) is higher $1000 \mathrm{ml}$ than after a vaginal delivery 500 $\mathrm{ml}$ and approximately $6 \%$ of women experience excessive blood loss as indicated by $10 \%$ or more drop in haematocrit after CD. ${ }^{2,4,5}$ Thus, the importance of measures to reduce the incidence and severity of $\mathrm{PPH}$ 
after CD cannot be overemphasized. ${ }^{6,7}$ So, vaginal delivery should be preferred to $\mathrm{CD}$ in anaemic women.

PPH can also result in conditions like iron deficiency anaemia, pituitary infarction (Sheehan's syndrome) with associated poor lactation, exposure to blood products, coagulopathy, and organ damage with associated hypotension and shock. ${ }^{8}$ Several strategies have reduced postpartum blood loss and the incidence of severe postpartum haemorrhage. There may be one or more causes for PPH related to four Ts', tone, tissue, trauma, thrombin. The most common cause of primary $\mathrm{PPH}$ is uterine atony, clinical examination should be done to exclude other or additional causes. Regardless of the cause of PPH, uterotonic drugs should be administered, followed by uterine massage, bimanual uterine compression to stimulate contraction. until the bleeding stops.

Active management of third-stage of labour (AMTSL), including early cord clamping and controlled cord traction and administration of uterotonic drugs such as oxytocin, with or without ergometrine, have been beneficial. ${ }^{9-11}$ Oxytocin is an essential and life-saving drug frequently used for women during childbirth, for the induction and augmentation of labour, to make childbirth safe and prevent death resulting from postpartum haemorrhage (PPH). Compared to expectant management, active management decreases the incidence of PPH by $70 \%$.

\section{Objective}

To study the drugs used in the management of postpartum haemorrhage at a tertiary care hospital.

\section{METHODS}

The institutional ethics committee approval was taken prior to initiation of the study. An observational and cross-sectional study design was adopted for this study. It was conducted over a period of two months January to February 2019. Oral informed consent was taken from all the patients before the patient's case sheets were analysed. The present study was conducted to study the drugs utilised in the management of post-partum haemorrhage at a tertiary care hospital. The present study was conducted in Government Maternity Hospital, Sultan Bazar, Koti which is a tertiary care hospital in Hyderabad.

The case sheets of 103 patients presenting in active stage of labour to labour room were analysed after taking informed oral consent from the patient. The case sheets were analysed to assess demographic data like Age and Kuppuswamy scale. Continuous variables such as gravida, parity and gestational age was noted. The risk factors for PPH i.e., previous history of post-partum haemorrhage (PPH) and pregnancy induced hypertension (PIH) were analysed. Patients were also assessed for the associated medical conditions like hypothyroidism, epilepsy, anaemia, Rh negative pregnancy. Obstetric complications noted were fetal bradycardia, polyhydramnios, preeclampsia, pregnancy induced hypertension $(\mathrm{PIH})$, fetal distress, post-dated pregnancy, premature rupture of membranes (PROM), post-dated pregnancy, low lying placenta with oligohydramnios. Obtained information was then compiled and analysed using World Health Organization (WHO) prescribing indicators, which included additional indices like commonest class/type of drugs prescribed and the various forms and dosages prescribed. ${ }^{13,14}$ The prescriptions were analysed with the help of descriptive statistics and results were expressed in percentage.

\section{Statistical analysis}

Data was entered and analysed with microsoft excel 2007. Descriptive statistics were used to analyse the results. Percentage and averages of the variable were also calculated to compare the data with other findings.

\section{RESULTS}

In this study 103 patients were analysed. The average number of patients between the age group 16-20, 21-25, 26-30 and 31-35 are $56(56 \%), 46(46 \%), 1(1 \%)$ and 0 respectively as shown in (Figure 1).

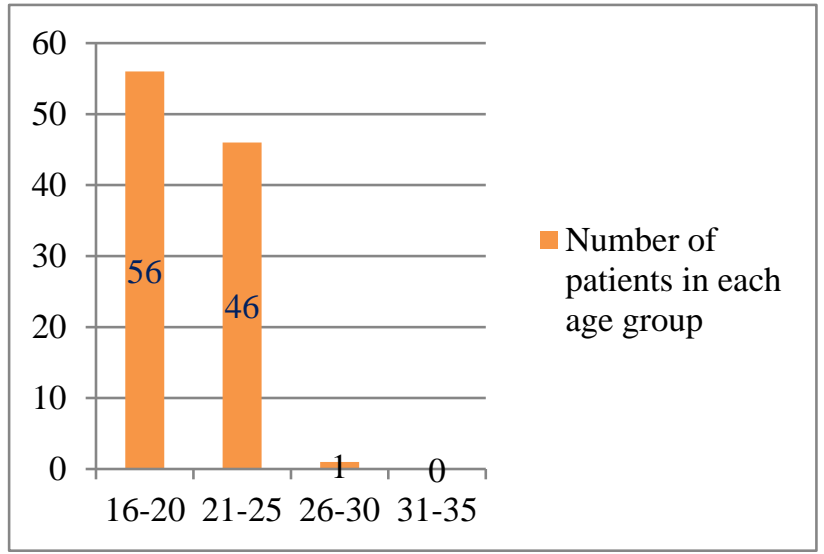

Figure 1: Age distribution of the study participants.

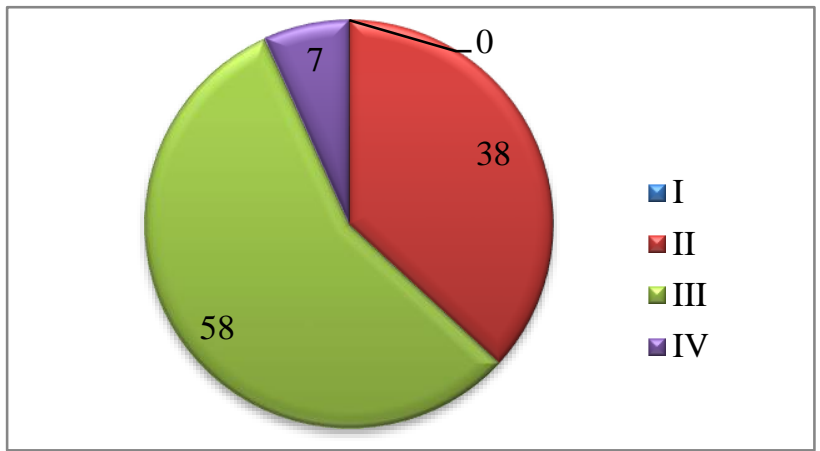

Figure 2: Kuppuswamy scale of the study participants. 
The socioeconomic status of the patients was classified in Kuppuswamy scale. According to it, they were graded as I, II, III and IV. The patients included in grade I was zero (0), grade II is $38(38 \%)$, grade III is $58(58 \%)$, grade IV is $7(7 \%)$, as shown in the above pie chart (Figure 2).

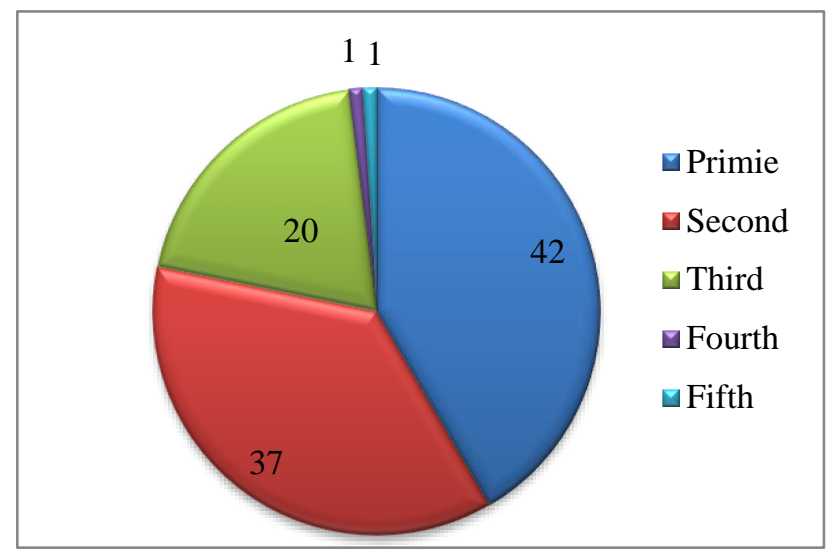

Figure 3: Parity of the study participants.

The patients included in primi, G2, G3, G4 and G5 are 42 (42\%), 37 (37\%), 20 (20\%), 1 (1\%) and 1 (1\%) respectively shown in (Figure 3).

Table1: Associated medical condition of the study participants.

\begin{tabular}{|ll|}
\hline Associated medical condition & Number of patients \\
\hline Rh-negative pregnancy & 1 \\
\hline Gestational hypertension & 7 \\
\hline Pre-eclampsia & 2 \\
\hline Polyhydramnios & 3 \\
\hline Hypothyroidism & 10 \\
\hline Anaemia & 4 \\
\hline
\end{tabular}

Among the 103 patients studied, 27 showed associated medical conditions. The medical conditions diagnosed in the patients were, one patient $3.7 \%$ had Rh-negative pregnancy, $7(25.9 \%)$ patients had gestational hypertension, $2(7.4 \%)$ patients had pre-eclampsia, 3 (11.1\%) patients with polyhydramnios, $10(37 \%)$ patients with hypothyroidism and $4(14.8 \%)$ patients had anemia as shown in (Table 1).

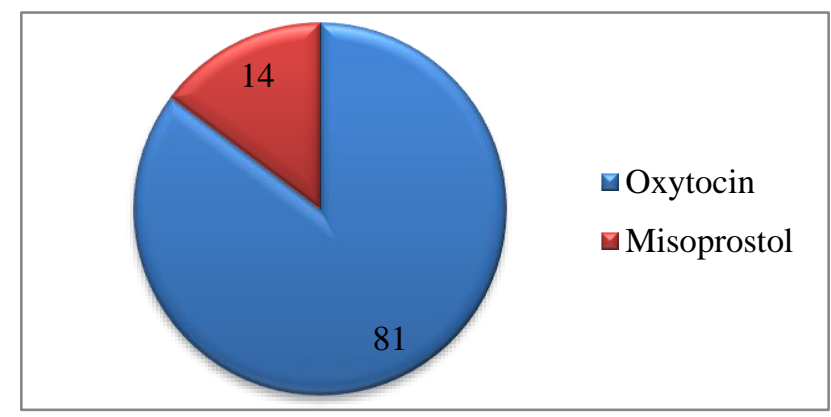

Figure 4: Drugs used to prevent PPH in the study participants.
In the prescriptions analysed from the patients in the labour room, drugs used to prevent PPH are oxytocin and misoprostol. Oxytocin is the most commonly prescribed drug. A total of 81 patients received only 10 IU oxytocin IM and 14 patients received 10 IU oxytocin IM and $600 \mathrm{~g}$ misoprostol to prevent PPH. As is shown in (Figure 4).

\section{DISCUSSION}

Oxytocin is an essential and life-saving drug frequently used for women during childbirth, for the induction and augmentation of labour, to make childbirth safe and prevent death resulting from postpartum haemorrhage (PPH). PPH contributes $38 \%$ approximately a total of 32,000 maternal deaths of all maternal deaths occurring every year in India. ${ }^{3,4}$ A recent report from the registrar general of India (RGI) showed that nearly 4 women die every hour in India from complications developed during childbirth, with heavy blood loss caused by haemorrhage being a major factor. ${ }^{3,4}$ Oxytocin is also important in a practice called "active management of third stage labour" (AMTSL). ${ }^{15}$ Since it cannot be predicted with certainty beforehand which woman is going to develop PPH after delivery, all standard guidelines, both internationally (WHO) and in India (GOI) recommend that the practice of AMTSL should be performed universally for all women, i.e., every woman should get a shot of oxytocin immediately after the birth of the baby in order to prevent PPH. ${ }^{16,17}$ The guidance note of the maternal health division, ministry of health and family welfare on prevention and management of postpartum haemorrhage recommends AMTSL for prevention of PPH and states that "oxytocin remains the uterotonic of choice for AMTSL. A uterotonic, is an agent used to induce contraction or greater tonicity of the uterus. Oxytocin (10 IU, IM) is the preferred uterotonic based on studies on the safety and effectiveness of uterotonics. It also is the recommended uterotonic drug for $\mathrm{PPH}$ prevention during caesarean sections". ${ }^{6}$

This study was done in a tertiary care maternity hospital, the study group consisted of 103 patients. A total of 81 patients received only $10 \mathrm{IU}$ oxytocin IM and 14 patients received $10 \mathrm{IU}$ oxytocin $\mathrm{IM}$ and $600 \mathrm{~g}$ misoprostol to prevent PPH. None of the patients had past history of PPH and PIH in the previous pregnancy, both of which are risk factors are $\mathrm{PPH}$. Routine prophylactic use of oxytocin reduces the incidence of PPH by approximately $40 \%$ resulting in decrease in maternal morbidity and mortality. ${ }^{11}$

Conventional uterotonics used include oxytocin, ergometrine, syntometrine (which consists of 5 IU oxytocin syntocinon and $0.5 \mathrm{mg}$ ergometrine), prostaglandin $\mathrm{F}_{2 \alpha}$ and prostaglandin $\mathrm{E}_{2}$. Oxytocin must be administered intramuscularly or intravenously, requires cold storage between $2-8^{\circ} \mathrm{C}$, lacks stability in tropical conditions. Ergometrine has been ineffective when administered orally, ergot preparations require 
refrigeration and protection against light to preserve their effectiveness.

The order issued by, government of India, ministry of health and family welfare department of health and family welfare (drugs regulation section) regarding sale of oxytocin. ${ }^{18}$ The government has restricted the manufacture of oxytocin formulations for domestic use to public sector only from $1^{\text {st }}$ September 2018, due to complaints of misuse. Karnataka antibiotics and pharmaceuticals ltd (KAPL), a PSU, would be manufacturing this drug for human and veterinary use. The drug will be supplied by KAPL to the registered hospitals and clinics in public and private sector. This drug will not be sold through retail pharmacies. All central government, state government and union territory agencies dealing with the procurement of medical products have also been authorized to procure oxytocin from KAPL for further supply to the registered hospitals and clinics in public and private sectors, in addition to Jan Aushadhi and AMRIT stores. ${ }^{18}$

The above order issued caused lot of hardship and risk to pregnant women as oxytocin is the most widely and commonly used drug to prevent $\mathrm{PPH}$ in our country. The immediate trigger for the series of orders leading up to the impugned notification was its purported misuse and consequent threat to the health and well-being of milch cattle. The injection of oxytocin into cattle was feared to leave residues of the drug in the milk produced, which was considered harmful to human health, as it could lead to male impotence, early puberty among women and cancers.

A petitioner in Delhi high court cited studies by scientists from the Indian council of agricultural research and national dairy research institute that showed that there was no evidence to support this apprehension. ${ }^{19}$ In a 2014 study, by the national institute of nutrition, Hyderabad, researchers found that oxytocin levels were similar in milk from cows injected with up to $1 \mathrm{IU}$ of the hormone and untreated cows. Plus, whatever little oxytocin was in the milk did not survive intestinal digestion. So, it is unlikely that humans would experience adverse effects due to oxytocin.

Oxytocin is an essential and life-saving drug required for preventing deaths of mothers during and immediately after delivery. Oxytocin has been misused widely in daily industry, agriculture and horticulture also exposure of milk consumers to oxytocin drug through dairy products. It has been used to increase the size of vegetables, fruits, such as watermelon, brinjals, pumpkins, gourds, cucumbers. It has been injected among trafficked girls in order to accelerate their puberty prematurely to speed up their sexual maturation. Sometimes oxytocin is used to compensate for stressful living conditions, which interferes with milk let-down. Also, because the synthetic oxytocin sold in pharmacies is expansive, farmers buy crude pituitary extract of hormone from grey market.
Such extracts contain several other hormones like gonadotropins, which have ill effects also. ${ }^{20}$ It has been illegally imported from China which operates out of Kolkata and Mumbai and subsequently sold in India in a crude plastic bottle by unregistered companies.

The decision to ban was taken in spite of research evidence and expert opinion to the contrary. In a country where more than half of all pregnant women are anaemic and with several states still unable to assure blood availability at all major delivery points, this would make women even more vulnerable and would lead to many more maternal deaths. ${ }^{20}$ After testing samples from milch animals, the scientists concluded that external injections of oxytocin into milch animals does not influence its content in the milk and the oxytocin present in the milk is actually rapidly degraded during digestion, ruling out its absorption and also adverse health consequences, if any. Research work from national diary research institute (NDRI) reported that there is no scientific evidence that artificial use of oxytocin has adversely affected pregnancy of cows and buffaloes.

The government gave KAPL the responsibility to manufacture the drug for both government and private supply. KAPL has never made the drug before, but it was given monopoly to produce the drug and the price of the drug would spike. There is need for massive surveillance and raid on illegal importers and unlicensed producers rather than a blanket ban. The sale of oxytocin needs to be curbed through constant surveillance by the regulatory authorities. There is a need for multiple layers of documentation as with narcotic and psychotropic drugs or antibiotics could be adopted. Its abuse needs to be curbed by means of restricting its sale for both human and veterinary purposes. There can be a restricted sale of oxytocin to hospitals in the public and private sector but not a total ban on private manufacture.

Oxytocin cannot be banned as it has a defined use for therapeutic purpose. The Government needed to consider the therapeutic uses of oxytocin in human being and its critical role in pregnant woman particularly at the postpartum stage before restricting the manufacture of oxytocin formulation.

\section{Limitation}

It was an observational and cross-sectional study design with limited sample size. The study was done in a Tertiary care hospital so, the prescribing patter in primary health care and district hospital could not be done. Also, the duration was short and the sample size was small which could have influenced the prescribing trend.

\section{CONCLUSION}

The study was conducted in a tertiary care government hospital where treatment is free of cost i.e., outpatient services, labour room, drugs and in-patient treatment are 
free. The government supply has all drugs used to prevent PPH, i.e. oxytocin, misoprostol, ergometrine and methergine. The drug used to prevent PPH was only oxytocin in 81 patients, oxytocin and misoprostol in 14 patients and only misoprostol in 2 patients. Oxytocin is the commonly and widely used drug to prevent PPH. Therefore, it is a life-saving drug to prevent $\mathrm{PPH}$ and thereby maternal mortality. So, it should not have been banned and not in the future. As there might be indiscriminate use of oxytocin in veterinary practice, oxytocin use should be checked by drug control authority like DCGA. Oxytocin is an essential drug included in the WHO essential drug list and in the national list of essential medicine. So, it shouldn't have been dealt in such a biased manner.

\section{ACKNOWLEDGEMENTS}

Authors would like to thank the faculty and Head of Department of Obstetrics and Gynaecology of the Institute for the permission, support and co-operation for the study.

\section{Funding: No funding sources} Conflict of interest: None declared

Ethical approval: The study was approved by the Institutional Ethics Committee

\section{REFERENCES}

1. Vimala N, Mittal S, Kumar S. Sublingual misoprostol versus oxytocin infusion to reduce blood loss at cesarean section. Int J Gynaecol Obstet. 2006;92:106.

2. Pritchard JA, Baldwin RM, Dickey JC. Blood volume change in pregnancy and the puerperium; red blood cell loss and changes in apparent blood volume during and following vaginal delivery, cesarean section and cesarean section plus total hysterectomy. Am J Obstet Gynecol. 1962;84:1272-82.

3. Lynn P, Freedman RJ, Waldman HP, Wirth ME. Who's got the power? Transforming health systems for women and children. UN Millenium Project Task Force Child Health Maternal Health. 2005:77-95.

4. Clark SL, Yeh SY, Phelan JP, Bruce S, Paul RH. Emergency hysterectomy for obstetric hemorrhage. Obstet Gynecol. 1984;64:376-80.

5. Combs CA, Murphy EL, Laros RK. Factors associated with postpartum hemorrhage with vaginal birth. Obstet Gynecol. 1991;77:69-76.

6. Ramanathan G, Arulkumaran S. Post-partum haemorrhage. Curr Obstet Gynaecol. 2006;16(1):613.

7. Kane TT, Kady EAA, Saleh S, Hage M, Stanback J, Potter L. Maternal mortality in Giza, Egypt: magnitude, causes, and prevention. Stud Fam Plann. 1992;23:45-57.

8. Shrestha A, Dongol A, Chawla CD, Adhikari RK. Rectal Misoprostol versus Intramuscular Oxytocin for Prevention of Post-Partum Hemorrhage. Kathmandu Univ Med J. 2011;9(33):1.

9. Rogers J, Wood J, McCandlish R, Ayers S, Truesdale A, Elbourne D. Active versus expectant management of third stage of labour: The Hinchingbrooke randomised controlled trial. Lancet. 1998;351:693-9.

10. Khan GQ, John IS, Wani S, Doherty T, Sibai BM. Controlled cord traction versus minimal intervention techniques in delivery of the placenta: A randomized controlled trial. Am J Obstet Gynecol. 1997;177:7704.

11. Nordstrom L, Fogelstam K, Fridman G, Larsson A, Rydhstroem H. Routine oxytocin in the third stage of labour: A placebo controlled randomized trial. $\mathrm{Br} \mathbf{J}$ Obstet Gynaecol. 1997;104:781-6.

12. Refaey EH, Noor R, Brien OP, Abdellah M, Geary $\mathrm{M}$, Walder J, et al. The misoprostol for third stage of labour study. Br J Obstet Gynecol. 2000;107:110410.

13. Walt RP. Misoprostol for the treatment of peptic ulcer and anti-inflammatory drug induced gastroduodenal ulceration. $\mathrm{N}$ Engl $\mathrm{J}$ Med. 1992;327:1575-80.

14. Zieman M, Fong SK, Benowitz NL, Bankster D, Darney PD. Absorption kinetics of misoprostol with oral or vaginal administration. Obstet Gynecol. 1997;90:88-92.

15. Surbek DV, Boesiger H, Hoesli I, Pavic N, Holzgreve W. A double-blind comparison of the safety and efficacy of intravaginal misoprostol and prostaglandin E2 to induce labour. Am J Obstet Gynecol. 1997;177:1018-23.

16. World Health Organization. WHO recommendations for the prevention and treatment of postpartum hemorrhage. Geneva: WHO; 2012. Available at https://apps.who.int/iris/bitstream/handle/10665/7541 1/9789241548502_eng.pdf; sequence $=1$. Accessed on 15 March 2019.

17. Maternal Health Division, Union Ministry of Health and Family Welfare. Guidance note on use of uterotonics during labour; 2015. Available at http://nhm.gov.in/images/pdf/programmes/maternalh ealth/guidelines/Guidance_Notes_on_Use_of_Uterot onics_during_labor.pdf. Accessed on 12 March 2019.

18. Government of India, Ministry of Health and Family Welfare, Department of Health and Family Welfare (Drugs Regulation Section) Nirman Bhawan, New Delhi Dated the 1 August 2018.

19. Pullakhandam R, Palika R, Vemula SR, Polasa K, Boindala S. Effect of Oxytocin injection to milching buffaloes on its content and stability in milk. Indian $\mathbf{J}$ Med Res. 2014;139(6):933-9.

20. The Hindu 18 August 2018 21:10 Ist. 2018.

Cite this article as: Lakshmi GNSS, Bharathi U, Sruthi V, Geervani A. Drug utilization study of drugs used in the management of post-partum hemorrhage at a tertiary care hospital. Int J Basic Clin Pharmacol 2020;9:1236-40. 